\title{
КУРЕНИЕ КАК ФАКТОР СОКРАЩЕНИЯ ОЖИДАЕМОЙ ПРОДОЛЖИТЕЛЬНОСТИ ЖИЗНИ В РОССИИ
}

\author{
ПОЛИНА КУЗНЕЦОВА
}

\begin{abstract}
Курение является важным фактором предотвратимой смертности в России. Согласно расчетам автора с использованием международных оценок относительных рисков смертности и российских данных о распространенности курения, самооценке здоровья и смертности по причинам смерти в 2017 г. продолжительность жизни курильщиков по сравнению с никогда не курившими была на 5,25,3 года ниже, а продолжительность здоровой жизни - на 2,6-3,2 года ниже.

Начиная с 2005 г. значения показателей смертности, вызванной курением (количество смертей, стандартизованные коэффициенты смертности), стабильно снижались, в целом повторяя изменения смертности от всех причин, происходившие в этот период. Однако данные по всему населению скрывают существенные гендерные различия: основное снижение табачной смертности происходило среди мужчин. Эпидемия табакокурения среди мужчин началась раньше и сейчас находится на более зрелой стадии (спад) по сравнению с женской (стагнаџия или даже рост для отдельных групп).

С 2004 по 2017 г. продолжительность жизни курящих женщин выросла заметно больше (более чем на полтора года), чем для некурящих, хотя для мужчин подобной тенденции не наблюдалось. Декомпозиция различий в продолжительности жизни между курящими и некурящими показывает, что преимущество некурящих женщчи в основном сократилось в возрастном диапазоне от 50 до 69 лет и вызвано преимущественно изменением смертности от сердечно-сосудистых заболеваний. Умужчин аналогичное сокращение преимущества некурящих по сравнению с курильщиками приходится на более молодые возраста (от 40 до 64 лет). В более поздних возрастах некурящие компенсируют свое отставание в приросте ожидаемой продолжительности жизни (ОПЖ), однако, поскольку для женщин данный эффект проявляется позже, его влияния оказывается недостаточно и общий прирост ОПЖ курящих женщин в изучаемом периоде оказывается выше.
\end{abstract}

Ключевые слова: курение, смертность, причины смерти, продолжительность жизни, продолжительность здоровой жизни.

\section{ВВЕДЕНИЕ}

Курение является важным фактором предотвратимой смертности. Начинаясь, как правило, уже в подростковом возрасте ${ }^{1}$, к 30-35 годам оно становится причиной значимых различий в смертности между курильщиками и некурящими.

ПоЛИНА ОЛЕГОВНА КУЗНЕЦОВА (polina.kuznetsova29@gmail.com), ИНСТИТУТ СОЦИАЛЬНОГО АНАЛИЗА И ПРОГНОЗИРОВАНИЯ РАНХИГС, РОССИЯ.

СТАТЬЯ ПОСТУПИЛА В РЕДАКЦИЮ В АВГУСТЕ 2019 Г.

${ }^{1}$ Согласно расчетам автора по данным РМЭЗ за 2017 г. для вопроса «Вспомните, пожалуйста, когда Вы начали курить? Сколько Вам тогда было лет?», до 20 лет начали курить более 80\% текущих курильщиков среди мужчин и более $65 \%$ среди женщин. 
В силу большей распространенности курения среди мужчин (в 2017 г. согласно данным РМЭЗ в России курили 43\% мужчин и 14\% женщин ${ }^{2}$ ) особенно заметно курение влияет на мужскую смертность, в том числе в трудоспособных возрастах.

Длительные наблюдения за значительными группами курильщиков и некурящих в рамках проспективных обследований смертности, проводимых во многих странах на международных (см., например, (Oza et al. 2011; National Center... 2014) и на российских данных (Плавинский, Плавинская 2012; Константинов и др. 2007), позволили выделить ряд болезней, которые могут быть вызваны курением, и оценить, насколько риски смерти от этих болезней в определенных возрастах выше для курильщиков по сравнению с некурящими (см. пример оценок в таблице 1). Комбинируя такие оценки относительных рисков с данными о смертности по причинам смерти и о доле курящих среди различных половозрастных групп, можно определить вклад курения в общую смертность. Такие расчеты делались и раньше: так, например, (Масленникова, Оганов 2011) с применением подобной методики оценивали табачную смертность в 2009 г. как 278 тыс. человек или 14\% всех смертей.

Интерес вызывает влияние курения на ожидаемую продолжительность жизни (ОПЖ), равно как и на ожидаемую продолжительность здоровой жизни (ОПЗЖ). В данном исследовании предпринята попытка ответить на ряд вопросов. В частности, нас интересовало, в какой степени изменения продолжительности жизни в 2004-2017 гг. были обусловлены изменениями в смертности от болезней, вызываемых курением. Другим объектом исследования стала динамика ОПЖ и ОПЗЖ курильщиков и некурящих, a также еe гендерные особенности. В завершающем разделе статьи приводятся сравнительные данные о влиянии курения на продолжительность жизни в России и других странах (на примере США и Индии).

\section{ОБЗОР ЛИТЕРАТУРЫ}

Начиная с 2003 г., продолжительность жизни в России растет, это самый продолжительный период улучшения показателей смертности с середины 1960-х годов (Школьников и др. 2014). Сравнение со значениями полувековой давности не позволяет увидеть улучшения структуры смертности - возрастное распределение смертности от крупных классов причин практически не изменилось, что позволяет сделать вывод об отсутствии в России признаков совершившегося второго эпидемиологического перехода (Вишневский 2015).

В работе (Shkolnikov et al. 2013) отмечается, что улучшение динамики смертности в 2000-х годах были в основном обусловлены снижением смертности от сердечнососудистых заболеваний и внешних причин среди взрослых. Авторы отмечают более

\footnotetext{
2 Данные специализированных опросов по вопросам потребления табака, как правило, дают более высокие оценки, чем социологические обследования домохозяйств. В частности, в присутствии других родственников часть респондентов - чаще женщины и молодежь (Hwang et al. 2018) - могут скрывать факт своего курения (Perlman et al. 2007; Laatikainen, Vartiainen, Puska 1999). Согласно данным специализированного глобального опроса GATS (Всемирная организация здравоохранения 2016) в 2016 г. в России курили 50\% мужчин и $15 \%$ женщин.
} 
масштабный эффект снижения смертности от болезней кровообращения и в особенности от цереброваскулярных заболеваний в старших возрастах по сравнению с более ранними периодами улучшений показателей смертности (в 1995-1998 и 1985-1987 гг.), что делает современную ситуацию в России отчасти похожей на изменения как в странах Центральной Европы в 1990-2000-х годах, так и в западно-европейских странах в 1970-х годах, получившие название «сердечно-сосудистой революции», однако вопрос о том, насколько устойчивой является эта тенденция, остается открытым.

Те же авторы в исследовании (Школьников и др. 2014) отмечают, что избыточная смертность в России может быть сокращена, в том числе за счет дальнейшего сокращения потребления табака (наряду со снижение потребления алкоголя и ростом эффективности национальной системы здравоохранения).

В работе (Grigoriev et al. 2014) исследуются компоненты и факторы устойчивой тенденции к снижению смертности в России, наблюдаемой начиная с 2003 г. С использованием данных о смертности по причинам смерти были определены основные характеристики недавних улучшений - это совокупность факторов, обусловленных как изменением в поведении (снижение потребления алкоголя, улучшение рациона питания), так и реализацией политики здравоохранения (использование лекарств для снижения артериального давления, расширение доступа и использование высокотехнологичных медицинских и хирургических вмешательств), а также улучшением экономического положения населения. Авторы приходят к выводу, что, несмотря на определенное сходство российской тенденции с начальными этапами снижения смертности в ряде европейских стран (Франция, Польша и Эстония), нельзя исключать возможность возврата к стагнации смертности из-за недостаточной готовности власти и общества уделять адекватное внимание вопросам общественного здравоохранения.

Кроме того, сохраняется значительное отставание России в продолжительности жизни не только от развитых стран, но и от стран с похожим уровнем экономического развития. Так, ожидаемая продолжительность жизни в России находится существенно ниже уровня, предсказываемого кривой Престона, устанавливающей связь между ОПЖ и ВВП на душу населения. Согласно результатам, представленным в работе (Андреев, Школьников 2018), в 2010 г. разница между модельной и реальной продолжительностью жизни для России составляла 8,7 года и была самой высокой среди 57 стран, включенных в вычисления.

Значительное влияние курения на смертность многократно доказано, в том числе и на российских данных. Так, например, по результатам проспективного исследования смертности жителей Петербурга, проводившегося на протяжении 30 лет, смертность от всех причин среди мужчин для курильщиков более чем в два раза превышала смертность никогда не куривших (Плавинский, Плавинская 2012). Ретроспективное исследование мужской смертности в Томске в 1990-2001 гг. показало, что в возрасте 15-74 года курение увеличивает риск смерти в 1,5 раза, в трудоспособных возрастах - более чем в 2 раза (Ефимова и др. 2017). Женское курение не менее опасно: в проспективном исследовании смертности жительниц Москвы в возрасте от 20 лет и старше относительные риски 
смертности от всех причин для умеренно куривших и бросивших курить были оценены соответственно как 1,86 и 1,25 (Константинов и др. 2007).

В исследовании, выполненном на панельных данных национального репрезентативного обследования Российского мониторинга экономического положения и здоровья населения НИУ ВШЭ (далее РМЭЗ), было показано, что по масштабу влияния на смертность курение сопоставимо с неумеренным потреблением алкоголя: относительные риски смертности для курильщиков и респондентов с опасным типом потребления алкоголя соответственно составили 1,64 и 1,56 (Denisova 2010).

Табачная эпидемия в России началась еще в советское время, широко распространившись преимущественно среди мужчин. В 1990-е годы она продолжила набирать обороты: распространенность курения среди мужчин достигла максимальных значений и надолго на них остановилась, в то время как доля курящих женщин за этот период практически удвоилась (Perlman et al. 2007).

К концу 2000-х годов, когда негативные последствия массового курения стали очевидны не только экспертам, но и обществу в целом, политика табачного контроля была значительна усилена: был введен запрет на курение в общественных местах, запрещена реклама, стали заметно расти акцизы на сигареты и другие табачные изделия ${ }^{3}$. За последнее десятилетие в курении в России произошли заметные изменения: впервые за постсоветский период распространенность курения стала устойчиво снижаться.

В недавней работе (Quirmbach, Gerry 2016) сделан вывод о том, что динамика курения в России в целом повторяет основные этапы развития табачной эпидемии, наблюдавшиеся ранее в других странах. В частности, авторы отмечают изменение поведения различных поколений курильщиков, а также устойчивое снижение гендерных различий в распространенности курения.

\section{МЕТОДОЛОГИЯ}

\section{Данные}

При расчетах были использованы оценки относительных рисков смертности от ряда болезней, вызываемых курением, на данных второго раунда американского обследования по профилактике рака Cancer Prevention Study CPS II (Oza et al. 2011). Используемые значения относительных рисков представлены в таблице 1. Обследование CPS II проводилось Американским онкологическим обществом в течение 24 лет и включало наблюдения за 1,2 млн человек во всех 50 штатах, округе Колумбия и Пуэрто-Рико. Целью данного крупномасштабного проспективного обследования было изучение

\footnotetext{
${ }^{3}$ Большинство неакцизных мер, ограничивающих потребление табачных продуктов, были введены Федеральным законом №15-Ф3 «Об охране здоровья граждан от воздействия табачного дыма и последствий потребления табака» от 23 февраля 2013 г.

${ }^{4}$ Cм. (Calle et al. 2002), а также страницу, посвященную обследованию на сайте Американского онкологического общества URL: https://www.cancer.org/research/we-conduct-cancerresearch/epidemiology/cancer-prevention-study-2.html
} 
взаимосвязи между индивидуальными факторами и характеристиками образа жизни, включая питание и вредные привычки, и риском развития рака и других заболеваний.

В анкету обследования были включены вопросы о физических и демографических характеристиках респондентов, их личной и семейной истории болезни раком и другими заболеваниями, употреблении лекарств и витаминов, репродуктивном поведении женщин, работе на вредных производствах, пищевых привычках, курении и употреблении алкоголя, занятиях физкультурой и спортом и других аспектах личного поведения. За 24 года наблюдений (с 1982 по 2006 г.) в рамках обследования было зафиксировано 491188 смертей; причина смерти была получена для 99,3\% от их количества. Полученные с помощью данных обследования оценки относительных рисков смертности имеют существенно больший уровень детализации как по половозрастным группам, так и по перечню заболеваний по сравнению с аналогичными российскими проспективными обследованиями смертности (Плавинский, Плавинская 2012; Константинов и др. 2007; Ефимова и др. 2017).

Для оценки показателей распространенности курения и состояния здоровья были использованы данные РМЭЗ НИУ ВШЭ с 1994 по 2017 г.

Основным источником информации для оценки смертности от болезней, вызванных курением, является Российская база данных по рождаемости и смертности РЭШ ${ }^{6}$ (коэффициенты смертности по причинам смерти и среднегодовая численность населения для пятилетних половозрастных групп, 1994-2017 гг.).

\section{Оценка распространенности курения и плохого/хорошего здоровья по полу и возрасту}

Для оценки распространенности курения использовали данные РМЭЗ за 1994-2007 гг. Курящими считались респонденты, давшие положительный ответ на вопрос «Вы курите в настоящее время?», бывшими курильщиками - давшие отрицательный ответ на вопрос о курении в настоящее время и положительный ответ на вопрос «Вы курили когда-нибудь?».

В исследовательской литературе проблема учета отложенного эффекта курения на здоровье и смертность решается по-разному. Одним из возможных вариантов ее решения является подход Пето-Лопеса (Peto et al. 1992), предполагающий использование коэффициента воздействия курения (smoking impact ratio) SIR на здоровье населения. Значение коэффициента воздействия курения SIR определяется путем сопоставления смертности от рака легких в изучаемой популяции и в референтной группе, как правило, заимствованной из упоминаемого ранее американского обследования по профилактике

\footnotetext{
5 Российский мониторинг экономического положения и здоровья населения НИУ ВШЭ (RLMS HSE), проводимый Национальным исследовательским университетом «Высшая школа экономики» и ООО «Демоскоп» при участии Центра народонаселения Университета Северной Каролины в Чапел Хилле и Института социологии Федерального научно-исследовательского социологического центра РАН. (Сайты обследования RLMS HSE: URL: http:/www.cpc.unc.edu/projects/rlms и URL: http://www.hse.ru/rlms).

${ }^{6}$ URL: http://demogr.nes.ru/index.php/ru/demogr_indicat/data
} 
рака CPS II. Дело в том, что рак легких в подавляющем большинстве случаев вызван именно активным или пассивным курением. Уровень воздействия курения SIR определяется как:

$$
\operatorname{SIR}=\left[\left(\mathrm{C}_{\mathrm{LC}}-\mathrm{N}_{\mathrm{LC}}\right) /\left(\mathrm{S}_{\mathrm{LC}}^{*}-\mathrm{N}^{*}{ }_{\mathrm{LC}}\right)\right] \times\left(\mathrm{N}_{\mathrm{LC}}^{*} / \mathrm{N}_{\mathrm{LC}}\right),
$$

где $\mathrm{C}_{\mathrm{LC}}$ и $\mathrm{N}_{\mathrm{LC}}$ - коэффициенты смертности от рака легких для изучаемой группы населения в целом и для никогда не куривших соответственно, a $S_{L C}^{*}$ и $^{*}{ }_{L C}-$ коэффициенты смертности от рака легких для курильщиков и некурящих в контрольной группе. Поправочный множитель $\mathrm{N}_{\mathrm{LC}}^{*} / \mathrm{N}_{\mathrm{LC}}$ необходим в тех случаях, когда помимо курения существуют другие факторы, существенно влияющие на смертность от рака легких, например, использование угля для отопления и приготовления пищи, высокая распространенность пребывания населения в местах заключения и др.

В ходе нашего исследования была предпринята попытка применить метод SIR к российским данным, начиная с 2000-х годов, однако из-за очень высокого уровня смертности от рака легких в первой половине 2000-х накопленный негативный эффект курения для некоторых групп, в частности для мужчин 45-49 лет, оказывается выше 100\% (рисунок 1).

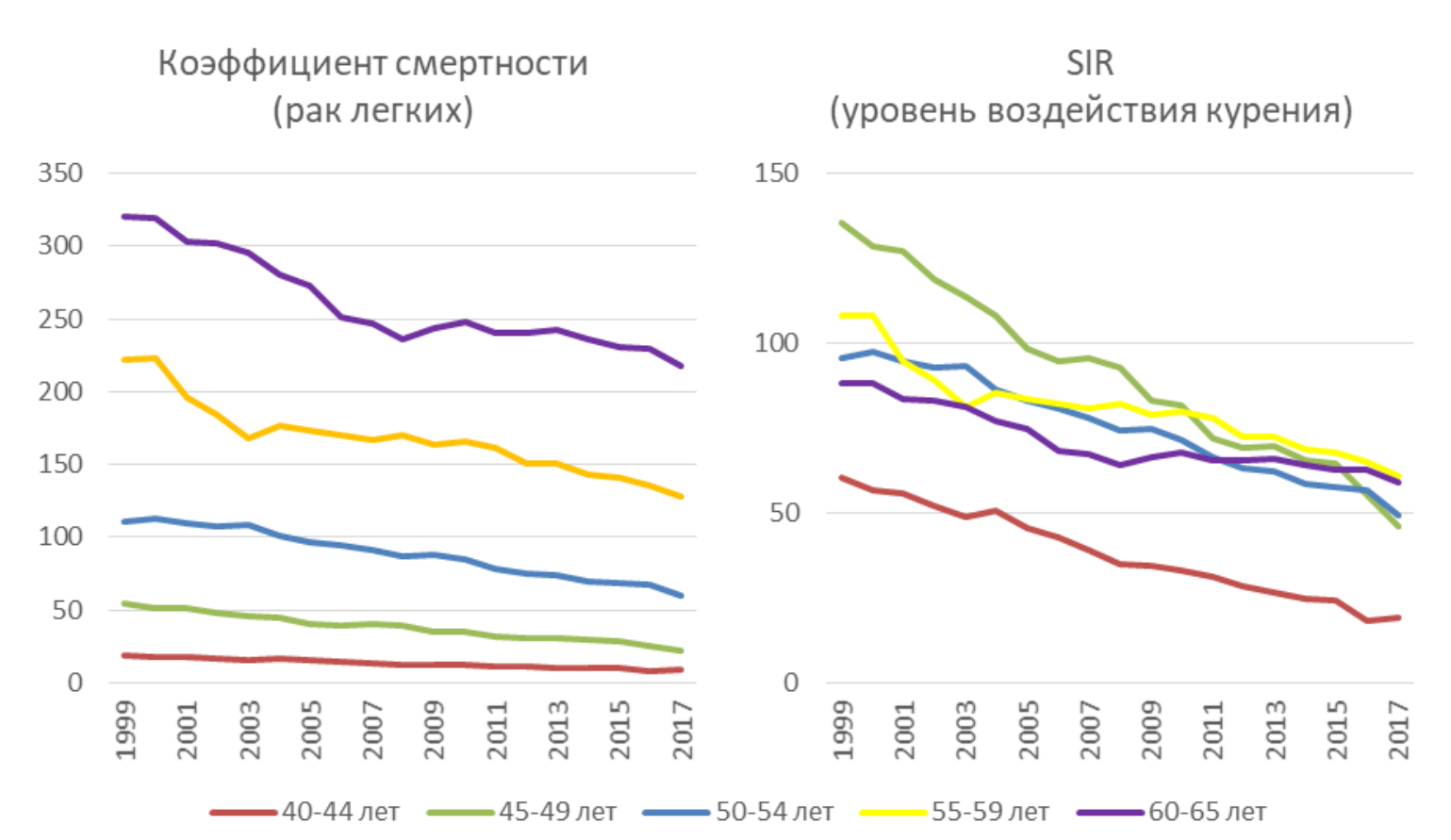

\section{Рисунок 1. Динамика мужской смертности от рака легких и определяемого на ее основе коэффициента воздействия курения (SIR), 1999-2017}

Источник: Расчеты автора на данных Российской базы данных о рождаемости и смертности.

В связи с невозможностью использовать коэффициент SIR долю населения, затронутого негативными последствиями курения, оценивали с помощью данных о распространенности курения (National Center... 2014; Oza et al. 2011). Многие авторы (Kong et al. 2016; Liutkute et al. 2017) для учета отложенного эффекта курения на здоровье и смертность используют данные о распространенности курения с лагом в 8, 10 или 20 лет. Период наблюдений за курением в РМЭЗ начинается с 1994 г., в связи с чем было принято 
решение использовать смещение в 10 лет, что позволяет отслеживать динамику показателя с 2004 по 2017 г.

Для оценки доли населения с плохим здоровьем были использованы данные РМЭЗ за 2004-2017 гг. Имеющими плохое здоровье считались респонденты, при ответе на вопрос «Как Вы оцениваете Ваше здоровье?» выбравшие варианты ответа «плохое» или «совсем плохое». Подобный способ оценки используется в утвержденной Росстатом методике расчета показателя «Ожидаемая продолжительность здоровой жизни (лет)» ${ }^{7}$.

Таблица 1. Относительные риски смертности от ряда болезней для курильщиков и бывших курильщиков по сравнению с никогда не курившими

\begin{tabular}{|c|c|c|c|c|}
\hline & \multicolumn{2}{|c|}{ Мужчины } & \multicolumn{2}{|c|}{ Женщины } \\
\hline & курили & $\begin{array}{c}\text { ранее } \\
\text { курили }\end{array}$ & курили & $\begin{array}{c}\text { ранее } \\
\text { курили }\end{array}$ \\
\hline \multicolumn{5}{|l|}{ Новообразования } \\
\hline трахеи, бронхов, легких (С33, С34) & 21,3 & 8,3 & 12,5 & 4,8 \\
\hline $\begin{array}{l}\text { губы, полости рта и глотки (C00-C14), пищевода (C15) и } \\
\text { гортани (С32) }\end{array}$ & 8,1 & 4,4 & 6,0 & 3,0 \\
\hline желудка (С16) & 2,16 & 1,55 & 1,49 & 1,36 \\
\hline печени (С22) & 2,33 & 1,81 & 1,5 & 1,69 \\
\hline поджелудочной железы (С25) & 2,2 & 1,2 & 2,2 & 1,6 \\
\hline шейки матки (С53) & 0 & 0 & 1,5 & 1,4 \\
\hline мочевого пузыря (С67) & 3,0 & 2,0 & 2,4 & 2,0 \\
\hline лейкемия (С91-С95) & 1,89 & 1,3 & 1,23 & 1,3 \\
\hline прямой кишки (С18-C21) & 1,32 & 1,15 & 1,41 & 1,22 \\
\hline почек и других мочевых органов & 2,5 & 1,8 & 1,5 & 1,2 \\
\hline \multicolumn{5}{|c|}{ Сердечно-сосудистые заболевания } \\
\hline Ишемическая болезнь сердца (I20-I25), 30-44 года & 5,51 & 1,18 & 2,26 & 2,22 \\
\hline Ишемическая болезнь сердца (I20-I25), 45-59 лет & 3,04 & 1,64 & 3,78 & 1,74 \\
\hline Ишемическая болезнь сердца (I20-I25), 60-69 лет & 1,88 & 1,29 & 2,53 & 1,34 \\
\hline Ишемическая болезнь сердца (I20-I25), 70-79 лет & 1,44 & 1,13 & 1,68 & 1,40 \\
\hline Ишемическая болезнь сердца (I20-I25), 80 лет и более & 1,05 & 1,02 & 1,38 & 1,40 \\
\hline Цереброваскулярные болезни (I60-I69), 30-44 года & 1 & 1 & 1 & 1 \\
\hline Цереброваскулярные болезни (I60-I69), 45-59 лет & 3,12 & 1 & 4,61 & 1,44 \\
\hline Цереброваскулярные болезни (I60-I69), 60-69 лет & 1,87 & 1,19 & 2,81 & 1,44 \\
\hline Цереброваскулярные болезни (I60-I69), 70-79 лет & 1,39 & 1 & 1,95 & 1,36 \\
\hline Цереброваскулярные болезни (I60-I69), 80 лет и старше & 1,05 & 1 & 1 & 1 \\
\hline Гипертоническая болезнь (I10-I15) & 1,96 & 1 & 2,12 & 1,12 \\
\hline $\begin{array}{l}\text { Прочие сердечно-сосудистые заболевания } \\
\text { (100-I09, I26-I51, I70-I99) }\end{array}$ & 2,15 & 1,3 & 2,0 & 1,34 \\
\hline \multicolumn{5}{|l|}{ Болезни органов дыхания } \\
\hline $\begin{array}{l}\text { Бронхит, эмфизема и другие хронические обструктивные } \\
\text { болезни легких (J20-J22, J40-J44) }\end{array}$ & 10,8 & 7,8 & 12,3 & 8,9 \\
\hline $\begin{array}{l}\text { Прочие болезни органов дыхания (пневмония, астма, грипп) } \\
\text { (J09-J18, J45-J46) }\end{array}$ & 1,9 & 1,4 & 2,2 & 1,2 \\
\hline Туберкулез (А15-А19) & 1,62 & 1,58 & 1,62 & 1,58 \\
\hline Диабет (E10-E14) & 1,42 & 1,1 & 1,14 & 1 \\
\hline
\end{tabular}

Источники: (Oza et al. 2011: table 1), а также (Ezzati et al. 2005a: table 1) - новообразования, (Thun, Apicella, Henley 2000: table 4) - болезни органов дыхания, (Ezzati et al. 2005b: table 1) - сердечнососудистые заболевания.

\footnotetext{
${ }^{7}$ Приказ Росстата от 25 февраля 2019 г. №95 «Об утверждении методики расчета показателя "Ожидаемая продолжительность здоровой жизни (лет)». URL:

http://www.consultant.ru/document/cons_doc_LAW_319186/076a4f37654d826be73fe6c5347bee3830e053a9/ 


\section{Смертность от болезней, вызванных курением}

Для оценки смертности от болезней, вызванных курением, был рассчитан коэффициент добавочного риска, обусловленного курением, PAF (population attributable fraction), отдельно по видам заболеваний и половозрастным группам:

$P A F_{i j}=\left(\left(p_{j}^{(0)}+p_{j}^{(1)} \times R R_{i j}^{(1)}+p_{j}^{(2)} \times R R_{i j}^{(2)}\right)-1\right) /\left(p_{j}^{(0)}+p_{j}^{(1)} \times R R_{i j}^{(1)}+p_{j}^{(2)} \times R R_{i j}^{(2)}\right)$,

где $p_{j}^{(0)}, p_{j}^{(1)}, p_{j}^{(2)}$ - распространенность курения в половозрастной группе ј среди никогда не куривших, бывших курильщиков и курящих соответственно, а $R R_{i j}^{(1)}$ и $R R_{i j}^{(2)}$ относительные риски смерти для бывших курильщиков и курящих от болезни $i$ в половозрастной группе $j$ по сравнению с никогда не курившими. Значения распространенности курения в зависимости от статуса курильщика для различных половозрастных групп были рассчитаны на данных РМЭЗ с лагом в 10 лет. Относительные риски смерти были заимствованы из исследований на данных обследования CPS II ((Oza et al. 2011: table 1) и др.), они представлены в таблице 1.

Количество добавочных смертей АM (mortality attributed to smoking) от данного заболевания рассчитывается как $A M=O M \times P A F$, где $\mathrm{OM}$ - общее количество смертей от данной причины смерти, взятое из официальных данных по смертности.

\section{Возрастные коэффициенты смертности для курильщиков, бывших курильщиков и некурящих}

Зная относительные риски смерти (RR), распространенность курения (p) и коэффициенты смертности по причинам смерти для пятилетних возрастных групп $\left(m^{\text {total }}\right)$, можно рассчитать коэффициенты смертности от болезни i для возрастной группы j для курильщиков $\left(m_{i j}^{(2)}\right)$, бывших курильщиков $\left(m_{i j}^{(1)}\right)$ и никогда не куривших $\left(m_{i j}^{(0)}\right)$ :

$m_{i j}^{(2)}=m_{i j}^{\text {total }} * \frac{p_{j}^{(2)} * R R_{i j}^{(2)}}{1-p_{j}^{(0)}+p_{j}^{(1)} * R R_{i j}^{(1)}+p_{j}^{(2)} * R R_{i j}^{(2)}}$

$m_{i j}^{(1)}=m_{i j}^{\text {total }} * \frac{p_{j}^{(1)} * R R_{i j}^{(1)}}{1-p_{j}^{(0)}+p_{j}^{(1)} * R R_{i j}^{(1)}+p_{j}^{(2)} * R R_{i j}^{(2)}} ;$

$m_{i j}^{(0)}=m_{i j}^{\text {total }} * \frac{p_{j}^{(0)}}{1-p_{j}^{(0)}+p_{j}^{(1)} * R R_{i j}^{(1)}+p_{j}^{(2)} * R R_{i j}^{(2)}}$.

Затем, используя стандартную технику построения таблиц смертности ${ }^{8}$, можно рассчитать продолжительность жизни для курильщиков, бывших курильщиков и никогда не куривших. Аналогично, разделяя совокупность живущих в каждом возрасте на имеющих

\footnotetext{
${ }^{8}$ Cм. (Preston, Heuveline, Guillot 2001: 49); при расчете ао для данного m0 использовали формулу АндрееваКингкейда из технического протокола Methods Protocol for the Human Mortality Database (Version 6), URL: https://www.mortality.org/Public/Docs/MethodsProtocol.pdf
} 
плохое здоровье и остальных, вычисляются значения ожидаемой продолжительности здоровой жизни для этих трех групп населения.

\section{Вклад изменений смертности по возрастным группам и причинам смерти в динамику ожидаемой продолжительности жсизни (метод декомпозиции)}

При анализе вклада в прирост продолжительности жизни изменений в смертности отдельных возрастных групп и смертности от различных причин был использован метод декомпозиции (Andreev, Shkolnikov, Begun 2002); см. также недавние примеры применения метода в работах (Timonin et al. 2017; Папанова, Школьников, Тимонин 2019). При расчетах использовали программу численной декомпозиции из технического доклада (Andreev, Shkolnikov 2012: пример 1: декомпозиция различий в продолжительности жизни при рождении по возрасту и причинам смерти для двух населений). Были рассмотрены два примера: 1) вклад в различия между продолжительностью жизни в 2004 и 2017 гг. болезней, вызванных курением; 2) вклад основных классов болезней в различия продолжительности жизни курильщиков и некурящих в 2004 и 2017 гг.

\section{РезУльтаты}

\section{Динамика показателей смертности, вызванной курением}

Начиная с 2004 г. в России наблюдался длительный период снижения смертности и роста продолжительности жизни, на фоне которого, согласно полученным расчетам, сокращалась и смертность от болезней, вызванных курением. Согласно полученным результатам, в 2017 г. курение стало непосредственной причиной 211,5 тыс. смертей среди мужчин и 23,4 тыс. смертей среди женщин (таблица 2). Абсолютные значения смертности, вызванной курением, начиная с 2005 г. стабильно снижались, в целом повторяя изменения, происходившие в этот период в смертности от всех причин. Однако данные по всему населению маскируют существенные гендерные различия: основное снижение табачной смертности происходило среди мужчин.

Одно из возможных объяснений происходящего предлагает теория табачной эпидемии (Lopez, Collishaw, Piha 1994). Эпидемия табакокурения среди мужчин началась раньше и сейчас находится на более зрелой стадии по сравнению с женской. Для женщин курение во многом продолжает оставаться одним из проявлений эмансипации или же, напротив, атрибутом более успешного мужского поведения, а также возможной борьбы со стрессом, лишним весом и др. Использование лагированных данных по распространенности курения (чтобы учесть отложенное влияние курения на здоровье, при расчетах рассматривали данные со смещением на 10 лет) лишь усиливает этот эффект. И если для мужчин курение в 1994-2007 гг. стабилизировалось (хотя и на очень высоких значениях), то доля курящих женщин в этот период заметно выросла. Как следствие, даже благоприятная динамика смертности от сердечно-сосудистых заболеваний второй половины 2000-х и 2010-х годов не позволила добиться снижения относительных 
показателей табачной смертности для женщин (рисунок 2); также см. (Калабихина, Кузнецова 2019).

Таблица 2. Распространенность курения, число умерших и стандартизованные коэффициенты смертности9 от болезней, вызванных курением. Россия, 2004-2017

\begin{tabular}{l|c|c|c|c|c|c}
\hline \multirow{2}{*}{ Год } & \multicolumn{2}{|c|}{$\begin{array}{c}\text { Pаспространенность курения, } \\
\text { \% (с лагом в 10 лет) }\end{array}$} & \multicolumn{2}{|c|}{$\begin{array}{c}\text { Умершие от болезней, } \\
\text { вызванных курением, чел. }\end{array}$} & \multicolumn{2}{|c}{$\begin{array}{c}\text { Стандартизованный } \\
\text { коэффициент смертности, на } \\
100000\end{array}$} \\
\cline { 2 - 7 } & мужчины & женщины & мужчины & женщины & мужчины & женщины \\
\hline 2004 & 57,6 & 9,2 & 296830 & 24401 & 492,0 & 24,4 \\
2005 & 59,6 & 9,1 & 301059 & 24730 & 494,3 & 25,4 \\
2006 & 59,7 & 9,8 & 276705 & 21666 & 453,4 & 22,2 \\
2007 & 59,3 & 10,2 & 263561 & 22984 & 430,8 & 22,9 \\
2008 & 58,8 & 10,5 & 263153 & 25001 & 429,8 & 24,8 \\
2009 & 58,9 & 11,1 & 253258 & 23138 & 413,7 & 23,6 \\
2010 & 58,9 & 11,7 & 249926 & 21598 & 404,2 & 22,8 \\
2011 & 59,9 & 14,3 & 239145 & 26044 & 379,9 & 25,7 \\
2012 & 60,9 & 14,2 & 232907 & 20618 & 366,3 & 21,5 \\
2013 & 60,6 & 15,0 & 229747 & 23376 & 355,6 & 23,1 \\
2014 & 60,1 & 15,6 & 226198 & 21403 & 345,7 & 21,8 \\
2015 & 59,9 & 15,2 & 225554 & 19182 & 333,7 & 19,9 \\
2016 & 60,4 & 15,7 & 224550 & 22817 & 325,8 & 22,6 \\
2017 & 59,9 & 15,9 & 211538 & 23368 & 303,5 & 22,5 \\
\hline
\end{tabular}

Источник: Расчеты автора.

Примечание: Данные о распространенности курения приводятся с запозданием в 10 лет с иелью учесть эффект отложенного влияния на здоровье.

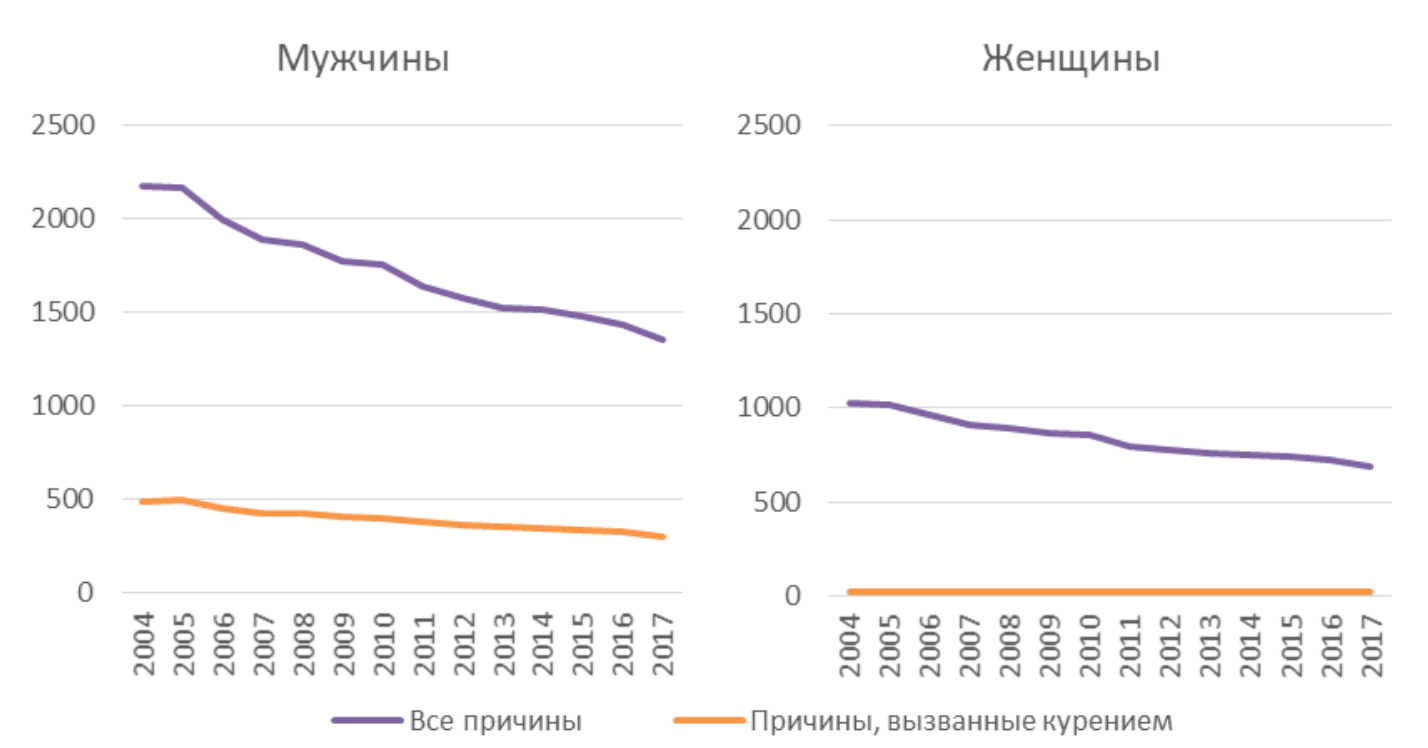

Рисунок 2. Стандартизированные коэффициенты смертности от всех причин и от болезней, вызванных курением, 2004-2017, на 100000

Источник: Расчеты автора.

\footnotetext{
${ }^{9}$ Использован европейский стандарт ВОЗ. См.: Росстат (1996). Методы стандартизации показателей естественного движения населения. Методические положения по статистике (выпуск 1, 2, 3, 4, 5). URL: http://www.gks.ru/bgd/free/B99_10/IssWWW.exe/Stg/d000/i000050r.htm
} 


\section{ДИНАМИКА ПОКАЗАТЕЛЕЙ ПРОДОЛЖИТЕЛЬНОСТИ ЖИЗНИ КУРИЛЬЩИКОВ И НЕКУРЯЩИХ}

Рассчитав таблицы смертности отдельно для курильщиков, бывших курильщиков и никогда не куривших (см. Приложение), можно сопоставить значения ОПЖ для этих трех групп, которые в совокупности дают все взрослое население. Наибольшие различия в продолжительности жизни, как и следовало ожидать, наблюдаются для курильщиков и никогда не куривших, составляя в 2017 г. 5,3 года для мужчин и 5,2 года для женщин. Факт отказа от курения существенно (на 2,6 года для мужчин и на 3,2 года для женщин) продлевает жизнь бросивших курить (таблица 3 ).

Таблица 3. Ожидаемая продолжительность жизни при рождении в зависимости от статуса курения, 2004-2017, лет

\begin{tabular}{|c|c|c|c|c|c|c|c|c|}
\hline \multirow[b]{2}{*}{ Год } & \multicolumn{4}{|c|}{ Мужчины } & \multicolumn{4}{|c|}{ Женщины } \\
\hline & $\begin{array}{c}\text { никогда } \\
\text { не курили }\end{array}$ & $\begin{array}{c}\text { ранее } \\
\text { курили }\end{array}$ & курят & $\begin{array}{c}\text { разность } \\
\text { (никогда } \\
\text { не курили/ } \\
\text { курят) }\end{array}$ & $\begin{array}{c}\text { никогда } \\
\text { не курили }\end{array}$ & $\begin{array}{c}\text { ранее } \\
\text { курили }\end{array}$ & курят & $\begin{array}{c}\text { разность } \\
\text { (никогда } \\
\text { не курили/ } \\
\text { курят), } \\
\text { лет }\end{array}$ \\
\hline 2004 & 62,6 & 60,1 & 57,2 & 5,4 & 72,7 & 69,3 & 65,9 & 6,7 \\
\hline 2005 & 62,6 & 60,2 & 57,3 & 5,4 & 72,8 & 69,3 & 66,1 & 6,7 \\
\hline 2006 & 64,1 & 61,7 & 58,8 & 5,4 & 73,6 & 70,2 & 67,1 & 6,5 \\
\hline 2007 & 65,2 & 62,7 & 59,8 & 5,4 & 74,4 & 71,0 & 68,0 & 6,3 \\
\hline 2008 & 65,6 & 63,1 & 60,2 & 5,4 & 74,7 & 71,3 & 68,3 & 6,3 \\
\hline 2009 & 66,6 & 64,0 & 61,1 & 5,5 & 75,2 & 71,7 & 69,0 & 6,2 \\
\hline 2010 & 66,8 & 64,3 & 61,4 & 5,4 & 75,3 & 71,9 & 69,4 & 5,9 \\
\hline 2011 & 67,8 & 65,2 & 62,3 & 5,5 & 76,1 & 73,0 & 69,9 & 6,2 \\
\hline 2012 & 68,3 & 65,8 & 62,9 & 5,4 & 76,4 & 73,2 & 70,5 & 5,8 \\
\hline 2013 & 68,9 & 66,3 & 63,5 & 5,5 & 76,8 & 73,7 & 70,9 & 6,0 \\
\hline 2014 & 68,9 & 66,4 & 63,6 & 5,4 & 77,0 & 74,4 & 71,3 & 5,7 \\
\hline 2015 & 69,5 & 66,9 & 64,2 & 5,3 & 77,2 & 74,4 & 72,3 & 4,9 \\
\hline 2016 & 70,1 & 67,6 & 64,9 & 5,3 & 77,6 & 74,3 & 72,2 & 5,3 \\
\hline 2017 & 71,1 & 68,5 & 65,9 & 5,3 & 78,2 & 75,0 & 73,0 & 5,2 \\
\hline
\end{tabular}

Источник: Расчеты автора.

Динамика показателей продолжительности здоровой жизни для курильщиков и некурящих представлена в таблице 4. Использовали методику, применяемую в российской официальной статистике, согласно которой здоровыми считаются люди, оценивающие свое здоровье как среднее, хорошее или очень хорошее. Продолжительность здоровой жизни как для курильщиков, так и для некурящих заметно ниже аналогичных показателей ОПЖ, причем особенно заметны различия для некурящих, поскольку их дополнительные по сравнению с курильщиками годы жизни приходятся на старость, когда самооценка здоровья резко снижается.

Как следствие, снижается вызванный курением разрыв в продолжительности жизни: если для ОПЖ в 2017 г. он составлял более 5 лет, то для ОПЗЖ - лишь 2,5-3 года. Продолжительность здоровой жизни курильщиков в зависимости от статуса курения в 2017 г. составила для мужчин 59,8 года для курильщиков и 62,8 года для некурящих, для женщин 63 года для курильщиков и 65,4 года для некурящих. Особо следует отметить значительный разрыв между продолжительностью жизни и продолжительностью здоровой 
жизни населения: даже для некурящих женщин, группы с наименьшими рисками смертности, ожидаемая продолжительность здоровой жизни едва превышает 65 лет. По крайней мере отчасти это объясняется особенностями используемого показателя доли здорового населения, основанного на самооценке респондентами своего здоровья.

Таблица 4. Сведения об ожидаемой продолжительности здоровой жизни в зависимости от статуса курения, 2004-2017, лет

\begin{tabular}{c|c|c|c|c|c|c}
\hline \multirow{2}{*}{ Год } & \multicolumn{3}{|c|}{ Мужчины } & \multicolumn{3}{c}{ Женщины } \\
\cline { 2 - 7 } & $\begin{array}{c}\text { никогда } \\
\text { не курили }\end{array}$ & курят & разность & $\begin{array}{c}\text { никогда } \\
\text { не курили }\end{array}$ & курят & разность \\
\hline 2004 & 55,1 & & 3,1 & 57,7 & 54,7 & 3,0 \\
2005 & 55,6 & 52,0 & 3,4 & 59,1 & 56,2 & 2,9 \\
2006 & 56,3 & 53,2 & 3,2 & 59,5 & 56,7 & 2,8 \\
2007 & 57,6 & 54,3 & 3,3 & 59,9 & 57,3 & 2,6 \\
2008 & 58,3 & 54,8 & 3,4 & 59,5 & 57,0 & 2,5 \\
2009 & 58,8 & 55,5 & 3,3 & 60,8 & 58,2 & 2,6 \\
2010 & 58,1 & 54,9 & 3,1 & 61,5 & 58,7 & 2,7 \\
2011 & 59,6 & 56,4 & 3,2 & 62,4 & 59,6 & 2,8 \\
2012 & 60,6 & 57,1 & 3,5 & 63,3 & 60,7 & 2,6 \\
2013 & 61,0 & 57,6 & 3,4 & 62,7 & 60,1 & 2,6 \\
2014 & 61,3 & 57,9 & 3,4 & 63,9 & 61,2 & 2,7 \\
2015 & 61,8 & 58,5 & 3,3 & 64,8 & 62,5 & 2,4 \\
2016 & 62,4 & 59,1 & 3,4 & 64,7 & 62,2 & 2,5 \\
2017 & 62,8 & 59,8 & 3,0 & 65,4 & 63,0 & 2,4 \\
\hline
\end{tabular}

Источник: Расчеты автора.

Проведенные оценки смертности от болезней, вызванных курением, имеют ряд ограничений. Так, при расчетах не учитывали пассивное курение, а также влияние, которое оказывает курение беременных женщин на здоровье их будущих детей. Другим важным ограничением является использование значений относительных рисков смертности для курильщиков по сравнению с некурящими, полученными для другой популяции (население США в 1982-2006 гг.). Точность полученных оценок напрямую зависит от качества данных РМЭЗ, используемых для расчета доли здорового населения и распространенности курения.

\section{ВКЛАД КУРЕНИЯ В ИЗМЕНЕНИЕ ПРОДОЛЖИТЕЛЬНОСТИ ЖИЗНИ В 2004-2017 ГГ.}

Прирост ожидаемой продолжительности жизни мужчин в 2017 г. по сравнению с 2004 г. в основном был обусловлен снижением смертности в старших трудоспособных возрастах с 40 до 60 лет, причем значительная часть этого улучшения была связана со снижением смертности от болезней, вызываемых курением (рисунок 3). Декомпозиция прироста ОПЖ женщин, напротив, показывает, что изменение смертности от болезней, вызванных курением, практически не оказывало влияния на оздоровление ситуации, а для некоторых возрастных групп (50-54 и 55-59 лет) даже способствовало некоторому снижению продолжительности жизни. 


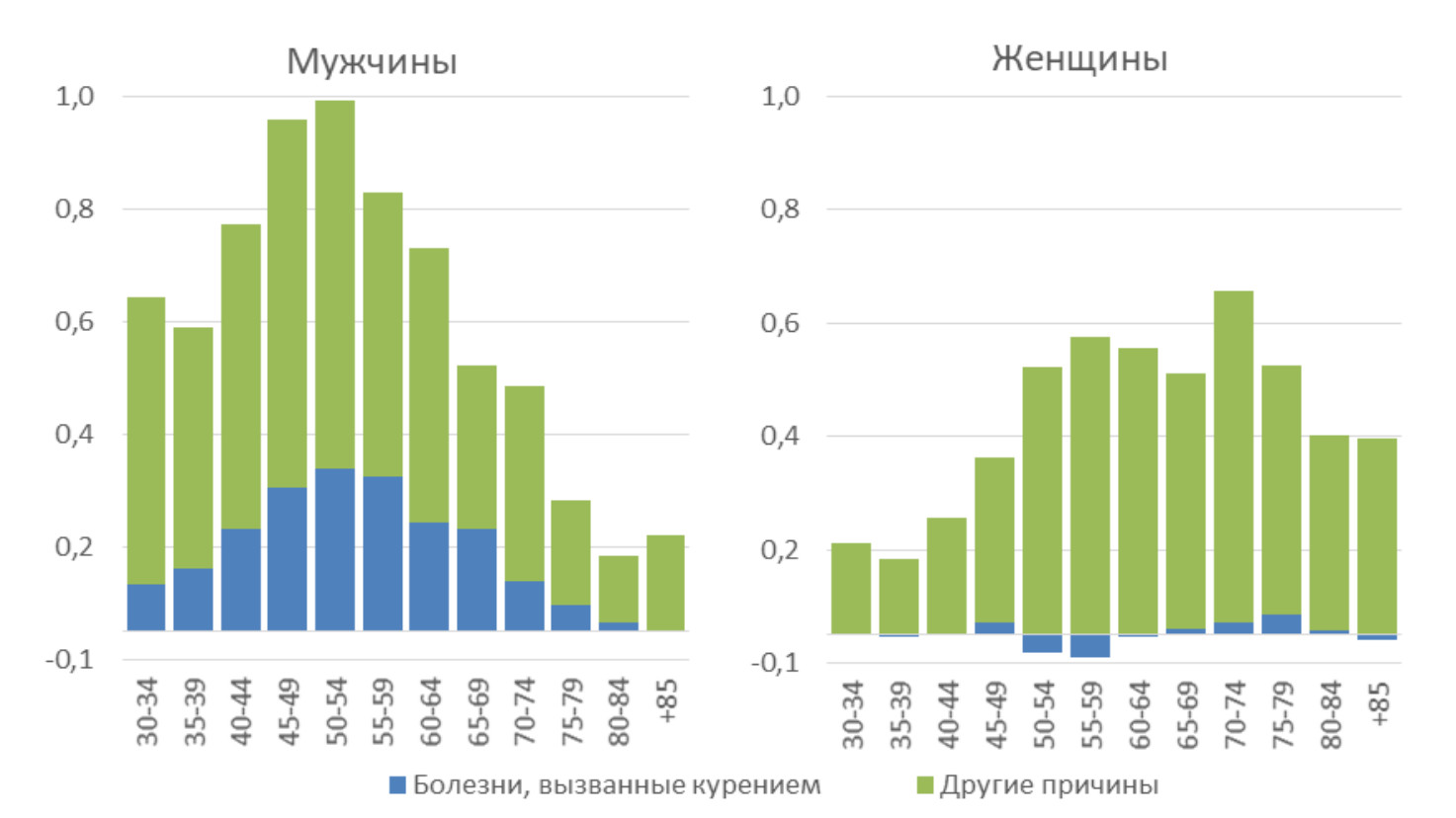

Рисунок 3. Вклад смертности от болезней, вызванных курением, в изменение продолжительности жизни мужчин и женщин, 2004-2017, годы

Источник: Расчеть автора.

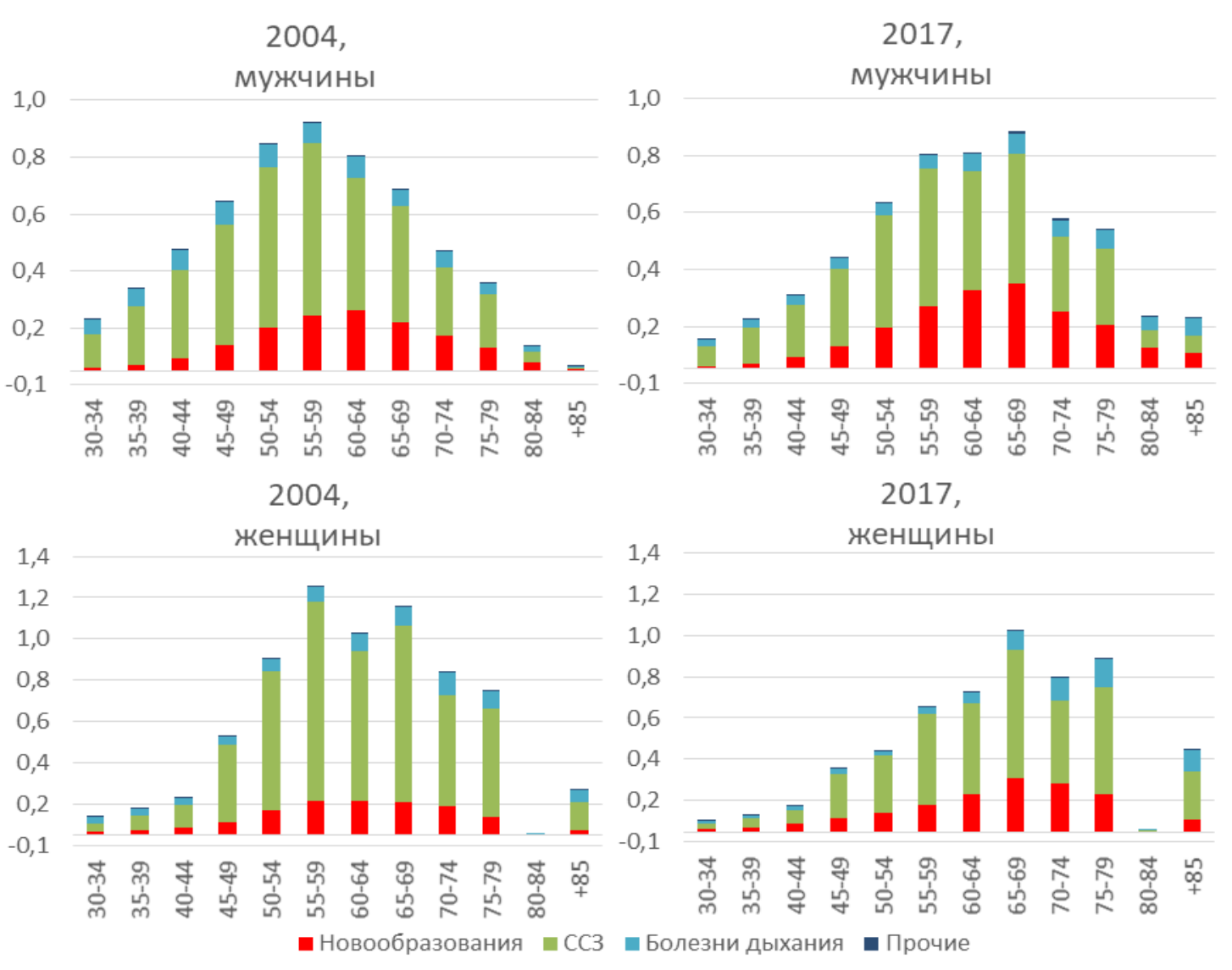

Рисунок 4. Вклад смертности от различных причин в различия в продолжительности жизни курильщиков и некурящих, 2004 и 2017

Источник: Расчеты автора. 
Особо отметим, что ожидаемая продолжительность жизни курящих женщин с 2004 по 2017 г. выросла больше, чем некурящих: рост для курящих и некурящих составил соответственно 7,1 и 5,5 года (таблица 3). Похожая динамика наблюдалась и для продолжительности здоровой жизни: преимущество некурящих над курящими сократилось на 0,5 года (таблица 4). Почему это произошло? Одно из возможных объяснений возникает при изучении вклада изменений смертности по возрастным группам и причинам смерти в динамику продолжительности жизни (рисунок 4) с помощью метода декомпозиции. Как видно из представленных данных, для курильщиков (как мужчин, так и женщин) в 2017 г., по сравнению с 2004 г., сократилось преимущество некурящих по сравнению с курильщиками в более молодых возрастах. В частности, особенно заметно преимущество некурящих женщин сократилось в возрастном диапазоне от 50 до 69 лет, что вызвано преимущественно изменением смертности от сердечно-сосудистых заболеваний. У мужчин аналогичное сокращение преимущества некурящих по сравнению с курильщиками приходится на более молодые возраста (от 40 до 64 лет). В более старших возрастах некурящие компенсируют свое отставание в приросте ОПЖ, однако, поскольку для женщин данный эффект проявляется позже, то его влияния оказывается недостаточно и общий прирост ОПЖ курящих женщин в изучаемом периоде оказывается выше.

\section{МЕЖДУНАРОДНЫЕ СРАВНЕНИЯ}

Для того, чтобы сравнить продолжительность жизни курильщиков и некурящих в России с другими странами, были использованы данные работы (Jha, Peto 2014: 62), в которой суммирована информация по четырем странам, где проводились национально репрезентативные исследования зависимости смертности от статуса курения умерших. Так, согласно результатам таких исследований, в Великобритании для мужчин 35 лет вероятность дожить до 80 лет составляет $60 \%$ для тех, кто никогда не курил, и $26 \%$ для курильщиков, а различия в продолжительности жизни для этих категорий составляют 10 лет. В Японии вероятность дожития составляет соответственно 68 и 41\% для некурящих и курильщиков, а разница в продолжительности жизни - 9 лет.

На рисунке 5 представлены сравнения ситуации в России с двумя другими странами, упомянутыми в статье (Jha, Peto 2014): с США (Jha et al. 2013) и Индией (Jha et al. 2008). США были выбраны как большая экономически развитая страна, Индия - как страна с более близким к России значением ожидаемой продолжительности жизни. Следует отметить, что для обеих стран речь идет об оценках смертности, вызванной курением, на начало 2000-х годов. Для Индии оценивали вероятности дожития до 70 лет, что более актуально в случае сравнения с российскими данными. Для мужчин они составили соответственно 59 и 39\% для некурящих и курильщиков (аналогичные значения для России составили соответственно 64 и 47\%). Особенностью Индии является практически полное отсутствие гендерных различий во влиянии курения на ОПЖ: доля доживающих до 70 лет среди женщин составляет 62 и 38\% для некурящих и курящих соответственно.

Сравнение доли доживающих до 80 лет с аналогичными американскими показателями демонстрирует существенное отставание России в ожидаемой 
продолжительности жизни некурящих. Если в США до 80 лет доживает 61\% тридцатилетних мужчин и 70\% женщин, то в России - лишь 37 и 57\% соответственно. Аналогичные значения для курильщиков существенно ближе: в США - 26\% мужчин и $38 \%$ женщин, в России - 20\% мужчин и $37 \%$ женщин. Это говорит о том, что, помимо курения, в России существуют и другие факторы, существенно снижающие продолжительность жизни, в том числе неумеренное потребление алкоголя и низкое качество общественного здравоохранения (Как преодолеть... 2016).
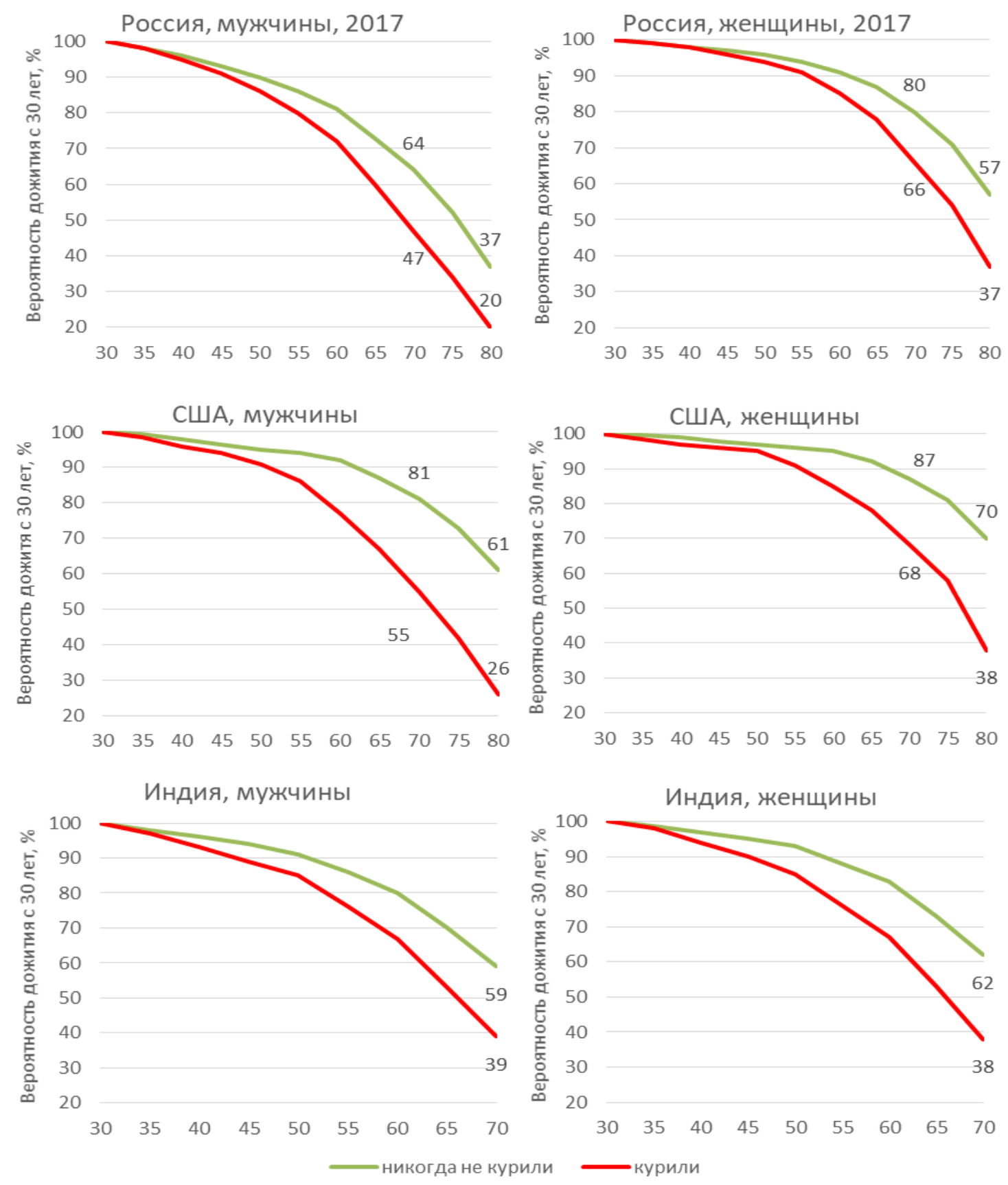

Рисунок 5. Вероятность дожития до определенного возраста для лиц, достигших 30 лет, в России, США и Индии

Источник: Россия - расчеты автора; США - (Jha et al. 2013), Индия - (Jha et al. 2008). 


\section{ЗАКЛЮЧЕНИЕ}

Курение является важным фактором предотвратимой смертности. Многолетние исследования, проводимые как в России, так и за рубежом, показывают, что курильщики сталкиваются с существенно более высокими рисками смертности от многих болезней сердечно-сосудистой системы, органов дыхания и новообразований. В данной работе дается количественная оценка влияния курения на смертность населения России в 2004-2017 гг. с использованием таких показателей, как стандартизованные коэффициенты смертности, ожидаемая продолжительность жизни и ожидаемая продолжительность здоровой жизни курильщиков и некурящих. Для оценок были использованы международные данные об относительных рисках смертности от различных заболеваний и российские данные о распространенности курения, плохого здоровья и смертности по причинам смерти.

Смертность от болезней, вызванных курением, согласно полученным оценкам, в 2017 г. превышала 230 тыс. человек, заметно снизившись по сравнению с началом 2000-х годов вслед за наблюдаемым в этот период снижением общей смертности от сердечнососудистых заболеваний. Смертность от курения среди женщин не снижалась, что объясняется менее зрелым характером табачной эпидемии среди женщин: начавшись позже, чем среди мужчин, она еще не достигла пиковых значений распространенности курения и вызываемой им смертности, а курение по-прежнему сохраняет привлекательность для многих девочек-подростков и молодых женщин.

Согласно проведенным расчетам, курение существенно сокращает продолжительность жизни. В 2017 г. различия в ожидаемой продолжительности жизни курильщиков по сравнению с никогда не курившими составили 5,3 года для мужчин и 5,2 года для женщин. Факт отказа от курения заметно (на 2,6 года для мужчин и на 3,2 года для женщин) продлевает жизнь бросивших курить.

По сравнению с 2004 г. ожидаемая продолжительность жизни курильщиков и некурящих существенно выросла, причем для курящих женщин рост продолжительности жизни оказался больше, в результате чего преимущество некурящих в продолжительности жизни в 2004-2017 гг. сократилось более чем на 1,5 года (здоровой жизни - на 0,5 года). Декомпозиция различий в продолжительности жизни между курящими и некурящими показывает, что преимущество некурящих женщин в основном сократилось в возрастном диапазоне от 50 до 69 лет, что вызвано, в первую очередь, изменением смертности от сердечно-сосудистых заболеваний. У мужчин аналогичное сокращение преимущества некурящих по сравнению с курильщиками приходится на более молодые возраста (от 40 до 64 лет). В более старших возрастах некурящие компенсируют свое отставание в приросте ожидаемой продолжительности жизни, однако, поскольку для женщин данный эффект проявляется позже, то его влияния оказывается недостаточным и общий прирост продолжительности жизни курящих женщин в изучаемом периоде оказывается выше.

По сравнению с развитыми странами (США, Великобритания, Япония), продолжительность жизни курильщиков и некурящих в России демонстрирует более заметные гендерные различия. Другой важной особенностью России является существенное отставание в продолжительности жизни некурящих. Если в США до 80 лет 
доживает 61\% тридцатилетних мужчин и 70\% женщин, то в России - лишь 37 и 57\% соответственно. Аналогичные значения для курильщиков существенно ближе, что дополнительно подтверждает существование в России, помимо курения, и других факторов, существенно снижающих продолжительность жизни, в том числе обусловленных образом жизни (злоупотребление алкоголем, несбалансированный рацион питания, несвоевременное обращение к врачу и др.).

\section{ЛИТЕРАТУРА}

Андреев Е.М., Школьников В.М. (2018). Связь между уровнями смертности и экономического развития в России и ее регионах. Демографическое обозрение, 5(1), 624. URL: https://doi.org/10.17323/demreview.v5i1.7707

Вишневский А.Г. (2015). Смертность в России: несостоявшаяся вторая эпидемиологическая революция. Демографическое обозрение, 1(4), 5-40. URL: https://doi.org/10.17323/demreview.v1i4.1801

Всемирная организация здравоохранения (ВО3) (2016). Глобальный опрос взрослого населения о потреблении табака: Российская Федерация. Краткий обзор. URL: http://www.euro.who.int/ru/countries/russian-federation/publications/global-adult-tobaccosurvey-russian-federation.-executive-summary-2016-2017 (данные загружены 14.06.2019).

Ефимова Е.В., Конобеевская И.Н., Максименко Г.В., Карпов Р.С. (2017). Курение и сердечно-сосудистая смертность населения в условиях Томска - типичного города Западной Сибири. Кардиоваскулярная терапия и профилактика, 16(6):115-121. URL: https://doi.org/10.15829/1728-8800-2017-6-115-121

Как преодолеть отставание России по продолжительности жизни? (2016).

Демографическое обозрение, 2(3), 154-201. URL:

https://doi.org/10.17323/demreview.v2i3.1778

Калабихина И.Е, Кузнецова П.О. (2019). Гендерные аспекты табачной эпидемии в России. Журнал Новой экономической ассоциации (статья принята к публикации, предположительно будет опубликована в №4)

Константинов В.В., Шальнова С.А., Киреев С.В., Тимофеева Т.Н., Шестов Д.Б., Капустина А.В., Баланова Ю.А., Лельчук И.Н., Деев А.Д. (2007). Относительный риск смертности среди женского населения в связи со статусом курения, употребления алкоголя и уровнем образования. Кардиоваскулярная терапия и профилактика, 6(3), 100-105.

Масленникова Г.Я., Оганов В.Г. (2011). Медицинский и социально-экономический ущерб, обусловленный курением табака в Российской Федерации: болезни системы кровообращения. Профилактическая медицина, 14(3), 19-27.

Папанова Е.К., Школьников В.М., Тимонин С.А. (2019). Особенности динамики и компоненты снижения смертности в Москве в 1989-2017 гг. Демографическое обозрение, 6(1), 50-103. URL: https://doi.org/10.17323/demreview.v6i1.9113

Плавинский С.Л., Плавинская С.И. (2012). Курение и смертность в крупном проспективном исследовании. Российский семейный врач, 16(2), 29-36.

Школьников В.М., Андреев Е.М., МакКи М., Леон Д.А. (2014). Рост продолжительности жизни в России 2000-х годов. Демографическое обозрение, 1(2), 5-37. URL: https://doi.org/10.17323/demreview.v1i2.1815 
Andreev E., Shkolnikov V., Begun A. (2002). Algorithm for decomposition of differences between aggregate demographic measures and its application to life expectancies, healthy life expectancies, parity-progression ratios and total fertility rates. Demographic Research, 7(14), 499-522. Retrieved from URL: https://dx.doi.org/10.4054/DemRes.2002.7.14

Andreev E.M., Shkolnikov V.M. (2012). An Excel spreadsheet for the decomposition of a difference between two values of an aggregate demographic measure by stepwise replacement running from young to old ages. Rostock: Max Planck Institute for Demographic Research (MPIDR Technical Report TR-2012-002). Retrieved from URL: https://www.demogr.mpg.de/papers/technicalreports/tr-2012-002.pdf

Calle E.. Rodriguez C., Jacobs E., Almon M. Chao A., Mccullough M., Feigelson H., Thun M. (2002). The American cancer society cancer prevention study II nutrition cohort: rationale, study design, and baseline characteristics. Cancer: Interdisciplinary International Journal of the American Cancer Society, 94(9), 2490-2501. doi: 10.1002/cncr.101970.

Denisova I. (2010) Adult mortality in Russia. The Economics of Transition, The European Bank for Reconstruction and Development, 18(2), 333-363. Retrieved from URL: https://doi.org/10.1111/j.1468-0351.2009.00384.x

Ezzati M., Henley J., Thun M.J., Lopez A.D. (2005b). Role of Smoking in Global and Regional Cardiovascular Mortality. Circulation. 112(4), 489-497. doi: 10.1161/CIRCULATIONAHA.104.521708

Ezzati M., Henley S.J., Lopez A.D., Thun M.J. (2005a). Role of smoking in global and regional cancer epidemiology: Current patterns and data needs. International journal of cancer, 116(6), 963-971. doi:10.1002/ijc.21100

Grigoriev P., Meslé F., Shkolnikov V., Andreev E., Fihel A., Pechholdova M., Vallin J. (2014). The Recent Mortality Decline in Russia: Beginning of the Cardiovascular Revolution? Population and Development Review, 40(1), 107-129. Retrieved from URL: https://doi.org/10.1111/j.1728-4457.2014.00652.x

Hwang J., Kim J., Lee D., Jung H. (2018). Underestimation of Self-Reported Smoking Prevalence in Korean Adolescents: Evidence from Gold Standard by Combined Method. International journal of environmental research and public health, 15(4), 689. Retrieved from URL:

Jha P., Jacob B., Gajalakshmi V., Gupta P. C., Dhingra N., Kumar R., Sinha D. N., Dikshit R. P., Parida D. K., Kamadod R., Boreham J., Peto R. (2008). A Nationally Representative CaseControl Study of Smoking and Death in India. New England Journal of Medicine, 358(11), 1137-1147. Retrieved from URL: https://doi.org/10.1056/NEJMsa0707719

Jha P., Peto R. (2014). Global Effects of Smoking, of Quitting, and of Taxing Tobacco. The New England Journal of Medicine, 370 (1), 60-68. doi:10.1056/NEJMra1308383.

Jha P., Ramasundarahettige C., Landsman V., Rostron B., Thun P., Peto R. (2013). 21st-Century hazards of smoking and benefits of cessation in the United States. New England Journal of Medicine, 368(4), 341-350. doi: 10.1056/NEJMsa1211128

Kong K., Jung-Choi K., Lim D., Lee H., Lee W., Baik S., Park S., Park H. (2016). Comparison of Prevalence- and Smoking Impact Ratio-Based Methods of Estimating SmokingAttributable Fractions of Deaths. Journal of epidemiology, 26(3), 145-54. doi: 10.2188/jea.JE20150058

Laatikainen T., Vartiainen E., Puska P. (1999). Comparing smoking and smoking cessation process in the Republic of Karelia, Russia and North Karelia, Finland. Journal of epidemiology and community health, 53(9), 528-534. doi:10.1136/jech.53.9.528 
Liutkute V., Veryga A., Štelemekas M., Goštautaite N. (2017). Burden of smoking in Lithuania: attributable mortality and years of potential life lost. European Journal of Public Health, 27(4), 736-741. doi: 10.1093/eurpub/ckx035

Lopez A., Collishaw N., Piha T. (1994). A descriptive model of the cigarette epidemic in developed countries. Tobacco Control, 3(3), 242-247. Retrieved from URL: http://dx.doi.org/10.1136/tc.3.3.242

National Center for Chronic Disease Prevention and Health Promotion (US) Office on Smoking and Health (2014). The Health Consequences of Smoking-50 Years of Progress: A Report of the Surgeon General. Atlanta (GA): Centers for Disease Control and Prevention (US), Chapter 12, Smoking-Attributable Morbidity, Mortality, and Economic Costs.

Oza S., Thun M., Henley J., Lopez A., Ezzati M. (2011). How many deaths are attributable to smoking in the United States? Comparison of methods for estimating smoking-attributable mortality when smoking prevalence changes. Preventive Medicine, 52 (6), 428-433. doi: 10.1016/j.ypmed.2011.04.007

Perlman F., Bobak M., Gilmore A. B., Mckee M. (2007). Trends in the prevalence of smoking in Russia during the transition to a market economy. Tobacco Control, 16(5), 299-305.

Retrieved from URL: https://dx.doi.org/10.1136\%2Ftc.2006.019455

Peto R., Lopez A., Boreham J., Thun M., Heath C., Doll R. (1992). Mortality from Tobacco in Developed Countries: Indirect Estimation from National Vital Statistics. Lancet, 339, 12681278.

Preston S., Heuveline P., Guillot M. (2001). Demography: Measuring and modeling population processes. Oxford: Wiley-Blackwell.

Quirmbach D., Gerry C. (2016). Gender, education and Russia's tobacco epidemic: A life-course approach. Social Science \& Medicine, 160, 54-66. Retrieved from URL: https://doi.org/10.1016/j.socscimed.2016.05.008

Shkolnikov V.M., Andreev E.M., McKee M., Leon D.A. (2013). Components and possible determinants of decrease in Russian mortality in 2004-2010. Demographic Research, 28(32), 917-950. Retrieved from URL: https://dx.doi.org/10.4054/DemRes.2013.28.32

Thun M.J, Apicella L.F., Henley S.J. (2000). Smoking vs Other Risk Factors as the Cause of Smoking-Attributable Deaths: Confounding in the Courtroom. Jama, 284(6),706-712. doi:10.1001/jama.284.6.706

Timonin S., Danilova I., Andreev E., Shkolnikov V.M. (2017). Recent Mortality Trend Reversal in Russia: Are Regions Following the Same Tempo? European Journal of Population, 33(5), 733-763. 


\section{ПРИЛОЖЕНИЕ}

П1. Данные о самооценке здоровья, РМЭЗ, 2004-2017 22.

Таблица П1.1. Распределение ответов на вопрос «Скажите, пожалуйста, как Вы оцениваете Ваше здоровье?», мужчины в возрасте 15 лет и старше

\begin{tabular}{l|c|c|c|c|c|c}
\hline Год & $\begin{array}{c}\text { Очень } \\
\text { хорошее }\end{array}$ & Хорошее & $\begin{array}{c}\text { Среднее, не хорошее, } \\
\text { но и не плохое }\end{array}$ & Плохое & $\begin{array}{c}\text { Очень } \\
\text { плохое }\end{array}$ & $\begin{array}{c}\text { Количество } \\
\text { наблюдений }\end{array}$ \\
\hline 2004 & 2,5 & 37,2 & 49,9 & 8,9 & 1,5 & 3179 \\
2005 & 2,7 & 38,8 & 48,2 & 8,6 & 1,7 & 3013 \\
2006 & 2,7 & 36,6 & 50,3 & 8,8 & 1,6 & 3841 \\
2007 & 3,2 & 37,9 & 48,7 & 8,5 & 1,7 & 3707 \\
2008 & 3,4 & 38,8 & 47,0 & 9,6 & 1,2 & 3504 \\
2009 & 3,7 & 35,9 & 49,9 & 9,3 & 1,2 & 3387 \\
2010 & 2,7 & 40,1 & 48,4 & 7,8 & 1,0 & 5922 \\
2011 & 3,0 & 39,6 & 47,0 & 9,0 & 1,3 & 5974 \\
2012 & 3,0 & 41,4 & 46,7 & 7,5 & 1,3 & 5899 \\
2013 & 2,8 & 41,4 & 46,6 & 8,1 & 1,1 & 5555 \\
2014 & 3,2 & 42,3 & 45,5 & 8,0 & 1,0 & 4522 \\
2015 & 3,4 & 43,2 & 44,5 & 7,6 & 1,3 & 4414 \\
2016 & 3,3 & 44,5 & 43,5 & 7,8 & 0,9 & 4355 \\
2017 & 3,5 & 45,0 & 43,0 & 7,4 & 1,2 & 4368 \\
\hline
\end{tabular}

Таблица П1.2. Распределение ответов на вопрос «Скажите, пожалуйста, как Вы оцениваете Ваше здоровье?», женщины в возрасте 15 лет и старше

\begin{tabular}{l|c|c|c|c|cc}
\hline Год & $\begin{array}{c}\text { Очень } \\
\text { хорошее }\end{array}$ & Хорошее & $\begin{array}{c}\text { Среднее, не хорошее, } \\
\text { но и не плохое }\end{array}$ & $\begin{array}{c}\text { Плохое } \\
\text { Очень } \\
\text { плохое }\end{array}$ & $\begin{array}{c}\text { Количество } \\
\text { наблюдений }\end{array}$ \\
\hline 2004 & 1,1 & 24,5 & 55,6 & 15,8 & 3,0 & 4359 \\
2005 & 1,7 & 26,2 & 54,2 & 15,1 & 2,7 & 4120 \\
2006 & 1,5 & 23,2 & 57,0 & 15,8 & 2,5 & 5324 \\
2007 & 2,1 & 25,4 & 54,7 & 15,0 & 2,8 & 5146 \\
2008 & 2,0 & 25,4 & 54,3 & 15,4 & 2,9 & 4971 \\
2009 & 2,1 & 25,6 & 55,1 & 15,0 & 2,1 & 4844 \\
2010 & 1,6 & 28,2 & 54,7 & 13,6 & 2,0 & 8180 \\
2011 & 1,8 & 29,3 & 52,4 & 14,4 & 2,1 & 8184 \\
2012 & 1,3 & 29,8 & 54,1 & 12,8 & 1,9 & 8290 \\
2013 & 1,2 & 30,3 & 53,1 & 13,5 & 2,0 & 7743 \\
2014 & 1,6 & 31,9 & 52,4 & 12,5 & 1,6 & 6212 \\
2015 & 1,2 & 32,0 & 52,6 & 12,5 & 1,6 & 6130 \\
2016 & 1,7 & 32,9 & 51,9 & 12,2 & 1,4 & 6093 \\
2017 & 1,6 & 35,1 & 50,0 & 11,7 & 1,7 & 6019 \\
\hline
\end{tabular}


П2. Таблицы смертности в зависимости от статуса курения

Таблица П2.1. Таблица смертности населения России (никогда не курили)

\begin{tabular}{|c|c|c|c|c|c|c|}
\hline \multirow[t]{2}{*}{ 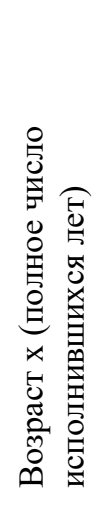 } & 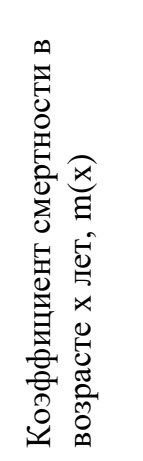 & 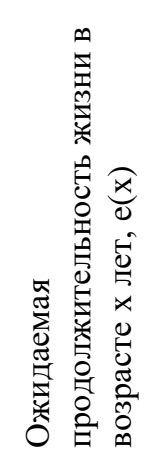 & 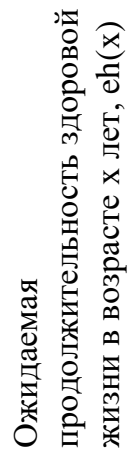 & 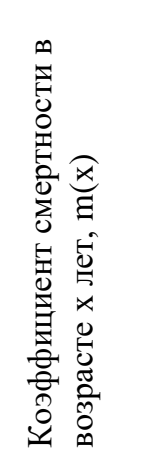 & 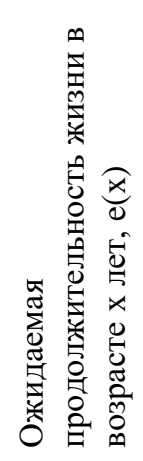 & 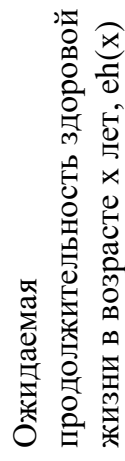 \\
\hline & \multicolumn{3}{|c|}{ Мужчины } & \multicolumn{3}{|c|}{ Женщины } \\
\hline 0 & 0,005911 & 71,1 & 62,8 & 0,004826 & 78,2 & 65,4 \\
\hline $1-4$ & 0,000371 & 70,5 & 62,2 & 0,000293 & 77,6 & 64,7 \\
\hline $5-9$ & 0,000226 & 66,7 & 58,4 & 0,000173 & 73,7 & 60,9 \\
\hline $10-14$ & 0,000311 & 61,7 & 53,5 & 0,000192 & 68,7 & 55,9 \\
\hline $15-19$ & 0,000867 & 56,8 & 48,7 & 0,000382 & 63,8 & 51,0 \\
\hline $20-24$ & 0,001547 & 52,1 & 43,9 & 0,000499 & 58,9 & 46,3 \\
\hline $25-29$ & 0,002394 & 47,4 & 39,4 & 0,000801 & 54,1 & 41,5 \\
\hline $30-34$ & 0,003579 & 43,0 & 34,9 & 0,001288 & 49,3 & 36,8 \\
\hline $35-39$ & 0,005331 & 38,7 & 30,7 & 0,001996 & 44,6 & 32,3 \\
\hline $40-44$ & 0,006262 & 34,7 & 26,7 & 0,002477 & 40,0 & 27,8 \\
\hline $45-49$ & 0,006899 & 30,7 & 22,8 & 0,003082 & 35,5 & 23,4 \\
\hline $50-54$ & 0,008935 & 26,7 & 18,8 & 0,003949 & 31,0 & 19,3 \\
\hline $55-59$ & 0,011818 & 22,8 & 15,1 & 0,006008 & 26,5 & 15,2 \\
\hline $60-64$ & 0,019486 & 19,0 & 11,5 & 0,009542 & 22,3 & 11,6 \\
\hline $65-69$ & 0,027453 & 15,7 & 8,6 & 0,015424 & 18,2 & 8,3 \\
\hline $70-74$ & 0,039438 & 12,7 & 6,3 & 0,024185 & 14,5 & 5,8 \\
\hline $75-79$ & 0,066309 & 9,9 & 4,1 & 0,045274 & 11,0 & 3,8 \\
\hline $80-84$ & 0,099167 & 7,9 & 2,6 & 0,077993 & 8,2 & 2,7 \\
\hline $85+$ & 0,15626 & 6,4 & 1,6 & 0,166846 & 6,0 & 2,1 \\
\hline
\end{tabular}

Источник: Расчеты автора. 
Таблица П2.2. Таблица смертности населения России (ранее курили)

\begin{tabular}{|c|c|c|c|c|c|c|}
\hline \multirow[t]{2}{*}{ 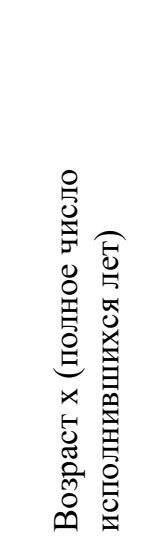 } & 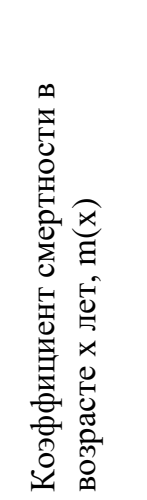 & 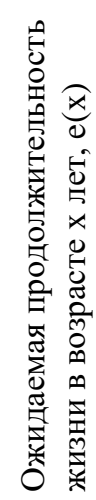 & 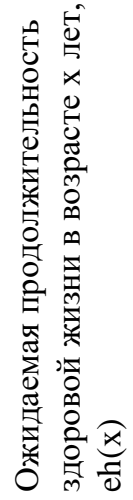 & 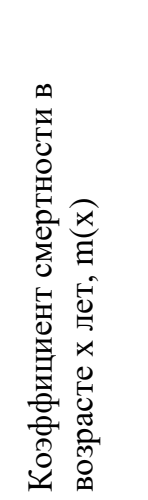 & 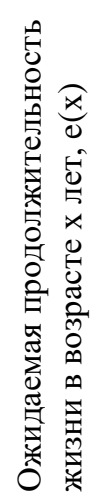 & 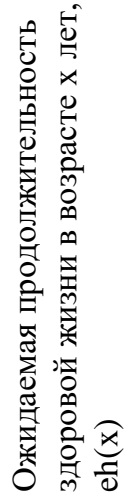 \\
\hline & \multicolumn{3}{|c|}{ Мужчины } & \multicolumn{3}{|c|}{ Женщины } \\
\hline 0 & 0,005911 & 68,5 & 61,4 & 0,004826 & 75,0 & 64,0 \\
\hline $1-4$ & 0,000371 & 67,9 & 60,8 & 0,000293 & 74,4 & 63,3 \\
\hline $5-9$ & 0,000226 & 64,0 & 57,0 & 0,000173 & 70,5 & 59,5 \\
\hline $10-14$ & 0,000311 & 59,1 & 52,1 & 0,000192 & 65,5 & 54,5 \\
\hline $15-19$ & 0,000867 & 54,2 & 47,3 & 0,000382 & 60,6 & 49,7 \\
\hline $20-24$ & 0,001547 & 49,4 & 42,5 & 0,000499 & 55,7 & 44,9 \\
\hline $25-29$ & 0,002394 & 44,8 & 37,9 & 0,000801 & 50,8 & 40,1 \\
\hline $30-34$ & 0,003749 & 40,3 & 33,5 & 0,001412 & 46,0 & 35,4 \\
\hline $35-39$ & 0,005653 & 36,0 & 29,2 & 0,002227 & 41,3 & 30,9 \\
\hline $40-44$ & 0,006801 & 32,0 & 25,2 & 0,002921 & 36,8 & 26,4 \\
\hline $45-49$ & 0,008137 & 28,0 & 21,3 & 0,003844 & 32,3 & 22,1 \\
\hline $50-54$ & 0,01136 & 24,1 & 17,4 & 0,00512 & 27,9 & 18,0 \\
\hline $55-59$ & 0,016065 & 20,3 & 13,9 & 0,008254 & 23,5 & 14,0 \\
\hline $60-64$ & 0,026408 & 16,8 & 10,4 & 0,01342 & 19,4 & 10,5 \\
\hline $65-69$ & 0,038495 & 13,8 & 7,8 & 0,023385 & 15,6 & 7,4 \\
\hline $70-74$ & 0,050101 & 11,2 & 5,8 & 0,036856 & 12,2 & 5,0 \\
\hline $75-79$ & 0,082651 & 8,8 & 3,7 & 0,067404 & 9,2 & 3,2 \\
\hline $80-84$ & 0,115421 & 7,0 & 2,4 & 0,102949 & 6,9 & 2,2 \\
\hline $85+$ & 0,176617 & 5,7 & 1,4 & 0,204242 & 4,9 & 1,7 \\
\hline
\end{tabular}

Источник: Расчеты автора. 
Таблица П2.3. Таблица смертности населения России (курят)

\begin{tabular}{|c|c|c|c|c|c|c|}
\hline \multirow[t]{2}{*}{ 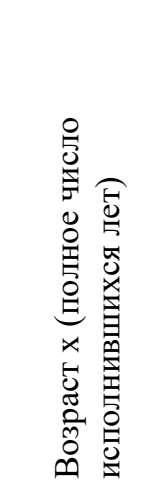 } & 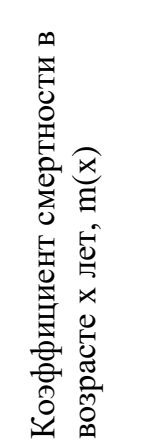 & 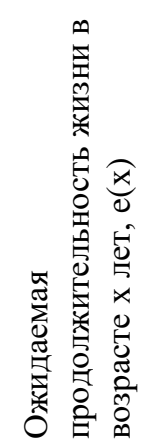 & 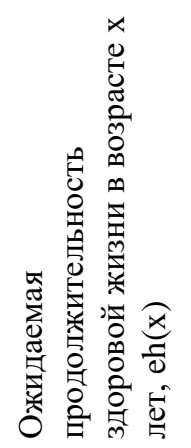 & 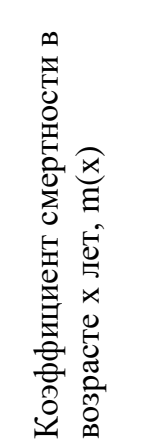 & 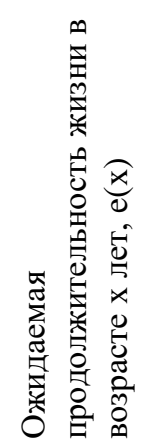 & 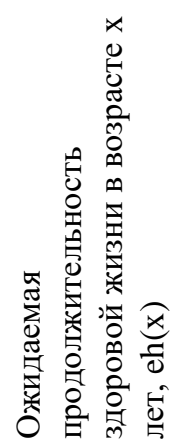 \\
\hline & \multicolumn{3}{|c|}{ Мужчины } & \multicolumn{3}{|c|}{ Женщины } \\
\hline 0 & 0,005911 & 65,9 & 59,8 & 0,004826 & 73,0 & 63,0 \\
\hline $1-4$ & 0,000371 & 65,3 & 59,1 & 0,000293 & 72,4 & 62,3 \\
\hline $5-9$ & 0,000226 & 61,4 & 55,3 & 0,000173 & 68,4 & 58,4 \\
\hline $10-14$ & 0,000311 & 56,4 & 50,5 & 0,000192 & 63,5 & 53,5 \\
\hline $15-19$ & 0,000867 & 51,5 & 45,6 & 0,000382 & 58,6 & 48,6 \\
\hline $20-24$ & 0,001547 & 46,7 & 40,8 & 0,000499 & 53,7 & 43,8 \\
\hline $25-29$ & 0,002394 & 42,1 & 36,2 & 0,000801 & 48,8 & 39,0 \\
\hline $30-34$ & 0,004139 & 37,5 & 31,8 & 0,001516 & 44,0 & 34,3 \\
\hline $35-39$ & 0,006428 & 33,3 & 27,5 & 0,002414 & 39,3 & 29,8 \\
\hline $40-44$ & 0,008173 & 29,3 & 23,6 & 0,003206 & 34,7 & 25,4 \\
\hline $45-49$ & 0,010341 & 25,4 & 19,8 & 0,005172 & 30,3 & 21,0 \\
\hline $50-54$ & 0,015302 & 21,6 & 16,1 & 0,007178 & 26,0 & 17,0 \\
\hline $55-59$ & 0,022355 & 18,1 & 12,7 & 0,012174 & 21,9 & 13,2 \\
\hline $60-64$ & 0,033825 & 15,0 & 9,5 & 0,018377 & 18,1 & 9,9 \\
\hline $65-69$ & 0,050056 & 12,3 & 7,0 & 0,032808 & 14,6 & 6,9 \\
\hline $70-74$ & 0,061839 & 10,1 & 5,3 & 0,043852 & 11,7 & 4,8 \\
\hline $75-79$ & 0,102422 & 7,9 & 3,4 & 0,081448 & 9,0 & 3,1 \\
\hline $80-84$ & 0,126366 & 6,5 & 2,2 & 0,078607 & 7,3 & 2,4 \\
\hline $85+$ & 0,189619 & 5,3 & 1,3 & 0,213850 & 4,7 & 1,6 \\
\hline
\end{tabular}

Источник: Расчеты автора. 


\title{
SMOKING AS A FACTOR OF REDUCED LIFE EXPECTANCY IN RUSSIA
}

\section{POLINA KUZNETSOVA}

\begin{abstract}
Smoking is an important factor of preventable mortality in Russia. According to the author's calculations, based on international estimates of the relative risks of mortality for smokers and Russian data on smoking prevalence, self-assessment of health and mortality by causes of death, in 2017 the life expectancy of smokers was 5.2-5.3 years lower than that of non-smokers, while the health life expectancy was 2.6-3.2 years lower.

Since 2005, smoking-related standardized mortality rates have been steadily declining, generally repeating the changes in mortality from all causes in Russia during this period. However, the aggregated data conceal significant gender differences - the main decrease in tobacco mortality was observed among men. The tobacco epidemic among men started earlier and is now at a more mature stage (decline) compared to the female one (stagnation or even growth for some groups).

From 2004 to 2017, the life expectancy of women smokers increased significantly more (by more than a year and a half) than for non-smokers, although for men such a trend is not observed. The decomposition of differences in life expectancy between smokers and non-smokers shows that the advantage in life expectancy of non-smoking women mainly decreased in the age range from 50 to 69 years, which is mainly caused by the changes in mortality from cardiovascular diseases. For men, a similar reduction of the advantage in life expectancy of non-smokers compared to smokers occurred at younger ages, from 40 to 64 years. At older ages, non-smokers reduce their lag in the increase of life expectancy, however, since for women this trend is observed later, its influence is insufficient, and as a result, life expectancy of women smokers in the study period grows faster.
\end{abstract}

Key words: smoking, mortality, causes of death, life expectancy, health life expectancy.

Polina KuZnetsova (polina.kuznetsova29@gmail.com), InstituTE FOR Social ANALYsis AND FoRECASTING AT RANEPA, RUSSIA.

DATE RECEIVED : AUGUST 2019.

\section{REFERENCES}

Andreev E., Shkolnikov V. (2018). The relationship between mortality and economic development in Russia and its regions. Demographic Review, 5(1), 6-24. (In Russ.). Retrieved from URL: https://doi.org/10.17323/demreview.v5i1.7707

Andreev E., Shkolnikov V., Begun A. (2002). Algorithm for decomposition of differences between aggregate demographic measures and its application to life expectancies, healthy life expectancies, parity-progression ratios and total fertility rates. Demographic Research, 7(14), 499-522. Retrieved from URL: https://dx.doi.org/10.4054/DemRes.2002.7.14

Andreev E.M., Shkolnikov V.M. (2012). An Excel spreadsheet for the decomposition of a difference between two values of an aggregate demographic measure by stepwise replacement running from young to old ages. Rostock: Max Planck Institute for Demographic Research (MPIDR Technical Report TR-2012-002). Retrieved from URL: https://www.demogr.mpg.de/papers/technicalreports/tr-2012-002.pdf

Calle E.. Rodriguez C., Jacobs E., Almon M. Chao A., Mccullough M., Feigelson H., Thun M. (2002). The American cancer society cancer prevention study II nutrition cohort: rationale, 
study design, and baseline characteristics. Cancer: Interdisciplinary International Journal of the American Cancer Society, 94(9), 2490-2501. doi: 10.1002/cncr.101970.

Denisova I. (2010) Adult mortality in Russia. The Economics of Transition, The European Bank for Reconstruction and Development, 18(2), 333-363. Retrieved from URL: https://doi.org/10.1111/j.1468-0351.2009.00384.x

Efimova E.V., Konobeevskaya I.N., Maksimenko G.V., Karpov R.S. (2017). Smoking and cardiovascular mortality in Tomsk inhabitants as a typical city of Western Siberia. Cardiovascular Therapy and Prevention, 16(6), 115-121. (In Russ.). Retrieved from URL: https://doi.org/10.15829/1728-8800-2017-6-115-121

Ezzati M., Henley J., Thun M.J., Lopez A.D. (2005b). Role of Smoking in Global and Regional Cardiovascular Mortality. Circulation. 112(4), 489-497. doi: 10.1161/CIRCULATIONAHA.104.521708

Ezzati M., Henley S.J., Lopez A.D., Thun M.J. (2005a). Role of smoking in global and regional cancer epidemiology: Current patterns and data needs. International journal of cancer, 116(6), 963-971. doi:10.1002/ijc.21100

Grigoriev P., Meslé F., Shkolnikov V., Andreev E., Fihel A., Pechholdova M., Vallin J. (2014). The Recent Mortality Decline in Russia: Beginning of the Cardiovascular Revolution? Population and Development Review, 40(1), 107-129. Retrieved from URL: https://doi.org/10.1111/j.1728-4457.2014.00652.x

How to overcome Russia's lag in life expectancy? (2016). Demographic Review, 2(3), 154-201. (In Russ.). Retrieved from URL: https://doi.org/10.17323/demreview.v2i3.1778

Hwang J., Kim J., Lee D., Jung H. (2018). Underestimation of Self-Reported Smoking Prevalence in Korean Adolescents: Evidence from Gold Standard by Combined Method. International journal of environmental research and public health, 15(4), 689. Retrieved from URL:

Jha P., Jacob B., Gajalakshmi V., Gupta P. C., Dhingra N., Kumar R., Sinha D. N., Dikshit R. P., Parida D. K., Kamadod R., Boreham J., Peto R. (2008). A Nationally Representative CaseControl Study of Smoking and Death in India. New England Journal of Medicine, 358(11), 1137-1147. Retrieved from URL: https://doi.org/10.1056/NEJMsa0707719

Jha P., Peto R. (2014). Global Effects of Smoking, of Quitting, and of Taxing Tobacco. The New England Journal of Medicine, 370 (1), 60-68. doi:10.1056/NEJMra1308383.

Jha P., Ramasundarahettige C., Landsman V., Rostron B., Thun P., Peto R. (2013). 21st-Century hazards of smoking and benefits of cessation in the United States. New England Journal of Medicine, 368(4), 341-350. doi: 10.1056/NEJMsa1211128

Kalabikhina I.E., Kuznetsova P.O. (2019). Gender aspects of tobacco epidemic in Russia. Journal of the New Economic Association (to be published in number 4). (In Russ.).

Kong K., Jung-Choi K., Lim D., Lee H., Lee W., Baik S., Park S., Park H. (2016). Comparison of Prevalence- and Smoking Impact Ratio-Based Methods of Estimating SmokingAttributable Fractions of Deaths. Journal of epidemiology, 26(3), 145-54. doi: 10.2188/jea.JE20150058

Konstantinov V.V., Shalnova S.A., Kireev C.V., Timofeeva T.N., Shestov D.B., Kapustina A.V., Balanova Yu.A., Lel'chuk I.N., Deev A.D. (2007). Associations of mortality relative risk, smoking status, alcohol intake, and educational level in women. Russian Journal of Preventive Medicine and Public Health, 14(3), 19-27. (In Russ.). 
Laatikainen T., Vartiainen E., Puska P. (1999). Comparing smoking and smoking cessation process in the Republic of Karelia, Russia and North Karelia, Finland. Journal of epidemiology and community health, 53(9), 528-534. doi:10.1136/jech.53.9.528

Liutkute V., Veryga A., Štelemekas M., Goštautaite N. (2017). Burden of smoking in Lithuania: attributable mortality and years of potential life lost. European Journal of Public Health, 27(4), 736-741. doi: 10.1093/eurpub/ckx035

Lopez A., Collishaw N., Piha T. (1994). A descriptive model of the cigarette epidemic in developed countries. Tobacco Control, 3(3), 242-247. Retrieved from URL: http://dx.doi.org/10.1136/tc.3.3.242

Maslennikova G.Ia., Oganov R.G. (2011). Medical and socioeconomic damage caused by smoking in the Russian Federation: diseases of circulatory system. Russian Journal of Preventive Medicine and Public Health, 14(3), 19-27. (In Russ.).

National Center for Chronic Disease Prevention and Health Promotion (US) Office on Smoking and Health (2014). The Health Consequences of Smoking - 50 Years of Progress: A Report of the Surgeon General. Atlanta (GA): Centers for Disease Control and Prevention (US), Chapter 12, Smoking-Attributable Morbidity, Mortality, and Economic Costs.

Oza S., Thun M., Henley J., Lopez A., Ezzati M. (2011). How many deaths are attributable to smoking in the United States? Comparison of methods for estimating smoking-attributable mortality when smoking prevalence changes. Preventive Medicine, 52 (6), 428-433. doi: 10.1016/j.ypmed.2011.04.007

Papanova E.K., Shkolnikov V.M., Timonin S.A. (2019). Distinctive features and components of mortality decrease in Moscow in 1989-2017. Demographic Review, 6(1), 50-103. (In Russ.). Retrieved from URL: https://doi.org/10.17323/demreview.v6i1.9113

Perlman F., Bobak M., Gilmore A. B., Mckee M. (2007). Trends in the prevalence of smoking in Russia during the transition to a market economy. Tobacco Control, 16(5), 299-305. Retrieved from URL: https://dx.doi.org/10.1136\%2Ftc.2006.019455

Peto R., Lopez A., Boreham J., Thun M., Heath C., Doll R. (1992) Mortality from Tobacco in Developed Countries: Indirect Estimation from National Vital Statistics. Lancet, 339, 12681278.

Plavinski S.L., Plavinskaya S.I. (2012). Smoking and mortality in a large prospective study. Russian family doctor, 16(2), 29-36. (In Russ.).

Preston S., Heuveline P., Guillot M. (2001). Demography: Measuring and modeling population processes. Oxford: Wiley-Blackwell.

Quirmbach D., Gerry C. (2016). Gender, education and Russia's tobacco epidemic: A life-course approach. Social Science \& Medicine, 160, 54-66. Retrieved from URL: https://doi.org/10.1016/j.socscimed.2016.05.008

Shkolnikov V.M., Andreev E.M., McKee M., Leon D.A. (2013). Components and possible determinants of decrease in Russian mortality in 2004-2010. Demographic Research, 28(32), 917-950. Retrieved from URL: https://dx.doi.org/10.4054/DemRes.2013.28.32

Shkolnikov V.M., Andreev E.M., McKee M., Leon D.A. (2014). Rising life expectancy in Russia of the 2000s. Demographic Review, 1(2), 5-37. (In Russ.). Retrieved from URL: https://doi.org/10.17323/demreview.v1i2.1815

Thun M.J, Apicella L.F., Henley S.J. (2000). Smoking vs Other Risk Factors as the Cause of Smoking-Attributable Deaths: Confounding in the Courtroom. Jama, 284(6),706-712. doi:10.1001/jama.284.6.706 
Timonin S., Danilova I., Andreev E., Shkolnikov V.M. (2017). Recent Mortality Trend Reversal in Russia: Are Regions Following the Same Tempo? European Journal of Population, 33(5), 733-763.

Vishnevsky A. (2015). Mortality in Russia: the second epidemiologic revolution that never was. Demographic Review, 1(4), 5-40. (In Russ.). Retrieved from URL: https://doi.org/10.17323/demreview.v1i4.1801

World Health Organization (WHO) (2016). Global Adult Tobacco Survey: Russian Federation. Executive Summary. (In Russ.). URL: http://www.euro.who.int/ru/countries/russianfederation/publications/global-adult-tobacco-survey-russian-federation.-executive-summary2016-2017 (data downloaded on 14.06.2019). 